\title{
AS MULHERES-ILHAS DE ORLANDA AMARILIS
}

\author{
Fabiana Miraz de Freitas Grecco
}

\begin{abstract}
RESUMO: Orlanda Amarílis nasceu em Assomada, Cabo Verde, 1924. Sua escrita é marcada pela narrativa curta, os contos. Pertenceu à geração da Revista Certeza (1944), periódico cabo-verdiano que se destacou por sua grande preocupação social. Ligada a esses propósitos, Amarílis criou, através de suas personagens femininas, uma nova maneira de tratar as questões da realidade cabo-verdiana. Testemunha-se por meio da sua escrita, o esmiuçar do cotidiano de mulheres exiladas, que buscam a sua identidade em um espaço alheio e distante. Dessa forma, procuraremos refletir, neste artigo, as questões sobre a identidade da mulher cabo-verdiana no conto "Maira da Luz", do livro A casa dos mastros, 1989, explicando como ocorre a "escrita pós-colonial de fronteira" na obra da escritora Orlanda Amarílis.
\end{abstract}

PALAVRAS-CHAVE: Contos. Pós-colonialismo. Literaturafeminina.

ABSTRACT: Orlanda Amarílis was born in Assomada, Cape Verde, 1924. She had started her writing career working to the Certeza magazine (1944), a Cape Verdean journal concerned with the social. Through of her female characters Amaryllis has created a new way of treat the questions of the cape verdean reality. In her short stories she shows the daily life of exiled women that seek their own identity in an alien and distant place. Thus, we will show in this article the questions about the identity of the cape verdean women in the short story entitled Maira da Luz, extracted from the storybook A casa dos Mastros, 1989. We will also explain the concept of "border-postcolonial-writing" in the work of Orlanda Amarílis.

KEYWORDS: Short stories. Post-colonialism. Women's literature.

\section{INTRODUÇÃO}

Não obstante sua importância para o sistema literário de seu país e, ainda, o fato de ser uma das mais importantes escritoras dos cinco países africanos de língua portuguesa, pouco se conhece da obra de Orlanda Amarílis, embora traduzida em vários países (Jane Tutikian 2007, p. 239).

Orlanda Amarílis nasceu em Assomada, cidade situada no conselho de Santa Catarina, na ilha de Santiago (Cabo Verde), a 8 de outubro de 1924. Viveu a maior parte de sua vida fora do arquipélago, tendo terminado os estudos do Magistério Primário em Goa e, depois, se formado em Pedagogia pela Faculdade de Letras de Lisboa, onde se estabeleceu. A sua obra está dispersa em revistas como Certeza (Cabo Verde 1944-1946), Colóquio Letras e Loreto 13 (Portugal) e $O$ Heraldo (Goa/Índia), por exemplo, e em antologias, quais sejam: Escrita e 
Combate (1976); Contos - O campo da palavra (1985); Fantástico no Feminino (1985). Além da obra dispersa, Amarílis tem publicado três livros de contos: Cais do Sodré té Salamansa (1974), Ilhéu dos Pássaros (1982), A casa dos mastros (1989).

Os contos de Orlanda são marcados pelo neorrealismo da geração da Revista Certeza (1944), periódico cabo-verdiano que se destacou pela grande preocupação social, e da qual foi uma das fundadoras. Sua obra foi traduzida para vários idiomas (italiano, russo, húngaro), e um deles "Luisa, filha de Nica" (Ilhéu dos Pássaros, 1992) foi emitido na Rádio Húngara com tradução e adaptação do professor Pal Ferenc, que publicou o livro "As Literaturas Africanas de Língua Portuguesa na Hungria”, 2007.

Amarílis cria uma nova maneira de tratar as questões do exílio, da diáspora e da insularidade próprios do povo caboverdiano, recorrendo à tradição africana, suas crenças religiosas e ao bilinguismo, que se divide entre a língua portuguesa e a língua cabo-verdiana, a fim de expressar literariamente a sua identidade. Assim, testemunha-se, por meio da sua escrita, o esmiuçar do cotidiano de mulheres exiladas, que questionam ou buscam a sua identidade em um espaço alheio e distante, recorrendo à memória para trazer à tona a casa, a sua pátria, como também a vida daquelas mulheres que ficaram nas ilhas, mostrando a união entre mães, filhas, tias, avós, amigas, lutando em um ambiente desfavorável.

De acordo com Simone Caputo Gomes, a mulher cabo-verdiana tem importância essencial "na construção, nas lutas de libertação e na emancipação do país" (GOMES 2008, p. 161). Seu papel é destacado, ainda, pela transmissão da cultura crioula e pela fixação da tradição oral. Nesse aspecto, Orlanda se insere entre essas mulheres, "que contam histórias de mulheres dentro da História do seu país. Daí a força da construção de suas personagens femininas" (TUTIKIAN 2007, p. 239). Não é por acaso que, na literatura, as mulheres caboverdianas constituem o maior número autores com publicações periódicas, fato que afirma a dispersão de textos das autoras, como Dina Salústio, Vera Duarte, Ana Júlia, Orlanda Amarílis entre outras.

De acordo com Benjamin Abdala Jr., em seu ensaio Globalização, Cultura $e$ Identidade em Orlanda Amarílis (2003, p. 287), as marcas femininas da autora se articulam "ao social e não o contrário, como acontecia com as obras de autoria masculina" (2003, p. 299) o que reforça a capacidade da autora em agravar "uma distonia anterior, que seria de gênero" (Idem). Dessa forma, procuraremos refletir, neste artigo, as questões sobre a 
identidade da mulher cabo-verdiana no conto "Maira da Luz", do livro A casa dos mastros, 1989, explicando como ocorre a "escrita pós-colonial de fronteira" na obra da escritora Orlanda Amarílis.

1. REALISMO FANTÁSTICO, ESCRITA DE AUTORIA FEMININA E A LÍNGUA CABO-VERDIANA

o que poderia ser denúncia da situação da mulher cabo-verdiana acaba também por constituir uma forma solidária de encontro. $\mathrm{O}$ texto, assim, não deixa de ser manifestação utópica: uma manifestação da vontade da escritora que acredita que as coisas possam ser diferentes do que são e se seus leitores, como suas personagens, não podem modificar o mundo, poderão pelo menos modificar suas atitudes diante dele (ABDALA JR. 1999, p. 9).

O livro de contos A casa dos mastros, de 1989, descreve o cotidiano de mulheres e homens das ilhas de Cabo Verde, sua relação com a pátria e o exílio. Contam ao todo sete contos: "Rodrigo", "A casa dos mastros", "Jack-Pé-de-Cabra", "Laura", "Bico-de-Lacre", "Tosca" e "Maira da Luz". O livro inicia-se com o conto "Rodrigo", que revela a vida de um moço "bem sabido", único "varão" da família, sempre rodeado de mulheres, deixando entrever sua veia boêmia nas noites em que escutava as mornas de Eugénio Tavares e seu gosto literário por obras brasileiras: compara-se a Rodrigo Cambará de "O tempo e o vento" do escritor gaúcho Érico Veríssimo.

Já no conto "A casa dos mastros", a narrativa é permeada pela violência e a referência ao poder patriarcal, ao colonialismo. O poder patriarcal está presente desde o mastro até o estupro da personagem principal, Violete, cujo nome próprio pode ser interpretado, pela raiz gramatical, como índice da violência da qual será acometida. Todos os contos do livro estão permeados de certo tom "fantástico", porém, em "Laura", o fantástico toma maiores proporções: a personagem principal morre duas vezes. Todas as narrativas atravessam, num movimento de vai-e-vem, Cabo Verde e Portugal, o real e o fantástico.

Orlanda revela em seus contos o que Pires Laranjeira, Ana Maria Martinho e Michel Laban chamaram de realismo fantástico, mesmo que venha a ser, essa afirmação científica dos críticos, questionada pela própria escritora. Em duas entrevistas, uma realizada por Michel Laban e publicada em 1992 sob o título "Cabo Verde: Encontro com Escritores, Vol I" e outra realizada pelo Seminário Internacional "Três vozes de Expressão Portuguesa", que 
se refere respectivamente a Helder Macedo, José Saramago e Orlanda Amarílis, ocorrido na UFRGS, em Porto Alegre, no ano de 1997, Orlanda é questionada sobre o aspecto do realismo fantástico em sua obra, a que responde nos dois momentos, respectivamente:

Eu teria gostado tanto do livro Água Mãe, talvez por nele ter encontrado uma identificação com nossa cultura, simbiose da cultura africana e europeia. Feitiçarias, bruxedos, mau-olhado, quebranto, tem raízes profundas em África, como sabe. A africanidade prevalece também nas nossas relações sociais, na nossa solidariedade espontânea, na nossa maneira de estar no mundo.

Ana Maria Martinho, professora em Lisboa de Literaturas Africanas de Língua Portuguesa, acrescenta que é um discurso literário tributário do fantástico em narrativa intimista. Será? Não seremos nós os juízes destas conjecturas.

A realidade que "começa a vacilar", como propõe Laban, conflui com o que se entende por realismo fantástico, de acordo com José Paulo Paes é "no mundo da normalidade que vai ocorrer de repente um fato inteiramente oposto às leis do real e às convenções do normal” (PAES 1985, p. 186). Apesar de Todorov criar uma teoria do fantástico “eminentemente restritiva”, Paes afirma que o fantástico, no século XX, já vem despido de seus compromissos com a hesitação todoroviana entre maravilhoso e estranho, pois agora ele "goza de plena liberdade para fazer o que queira" (Idem).

Mesmo contestando a marca do "realismo fantástico", Orlanda abre um caminho para a compreensão desse aspecto em seus contos: a semelhança com a cultura brasileira, a leitura da literatura brasileira e a existência da "simbiose" entre África e Europa. Desse modo, o fantástico em Orlanda Amarílis, estabelece-se conforme exprime Benjamin Abdala Jr., "vem de fontes culturais crioulas, na mescla do misticismo das culturas africanas com dos primitivos colonos portugueses que vieram ter ao arquipélago" (ABDALA JR. 2003, p. 293).

De acordo com os intelectuais cabo-verdianos, principalmente os pertencentes à época da Revista Claridade (1936-1960), no tocante à simbiose entre essas culturas, a "formação de uma população nova e uma civilização antes inexistente, só ocorreu no Brasil e em Cabo Verde" (LOPES, 1986, p. 16). A esse respeito, Benjamin Abdala Junior também explica tal semelhança de colonização entre Brasil e Cabo Verde:

Como o Brasil, Cabo Verde também possui uma cultura crioula - isto é, uma cultura formada de pedaços da cultura portuguesa e de várias culturas africanas, formando um todo mestiço não-unívoco, não-sintético, ao 
contrário do que acontece com povos de formação mais antiga (ABDALA Jr. 2003, p. 293).

Esse fator gerou no cabo-verdiano o gosto por exaltar tal parecença entre os dois países. Baseado nessa similaridade, surge o esforço do intelectual cabo-verdiano em sublinhar o orgulho de Brasil e Cabo Verde serem "países irmãos", que se exibe desde as primeiras manifestações literárias, tornando-se mais forte a partir da Revista Claridade (1936-1960), com a "importação de modelos estéticos e de identificação do modernismo brasileiro, especificamente do regionalismo de 1930" (GRECCO 2010, p. 17).

Orlanda Amarílis, em mesma entrevista a Michel Laban, reforça o intercâmbio ou mesmo, para enfatizar a maior necessidade dos escritores e intelectuais cabo-verdianos em beber toda literatura produzida no Brasil, a importação de obras brasileiras, afirma que "líamos quase tudo o que viesse do Brasil" e tendo ela se impressionado com o escritor José Lins do Rego, explica:

a realidade brasileira aproxima-se da de Cabo Verde, assim como a doçura (morabeza) de trato, a maneira 'gostosa' (sabe-de-mundo) de dizer as coisas. O fantástico, por exemplo, na Água Mãe quando se refere à Casa Azul. Pureza, uma estação isolada, longe de tudo, lembrava-me aqueles sítios isolados de Cabo Verde onde pequenos-nadas ganham foros de acontecimento. A vida nas fazendas, a cana-do-açúcar, o engenho (trapiche), etc., etc. (1992, p.265-266).

Dentre outros regionalistas brasileiros, Orlanda admirava a obra de Graciliano Ramos e Jorge Amado. Na poesia, Manuel Bandeira, Carlos Drummond de Andrade e João Cabral de Melo Neto. Ainda acrescenta Érico Veríssimo, explicando por que a narrativa de "O tempo e o vento" a arrebatou tanto, a ponto de traçar intertextualidade e citação em seu próprio conto Rodrigo, de A casa dos mastros:

Se gosto de Érico Veríssimo é porque "O tempo e o vento" me arrebatou. A Bibiana e a sua cadeira de baloiço, o sobrado com a mesma intimidade como os nossos em Cabo Verde, o Rodrigo que não merecia deixar a vida tão cedo (1992, p. 267).

A respeito de suas leituras de mulheres escritoras, cita-nos, nas mesmas entrevistas mencionadas, as que fazem parte de sua contemporaneidade e as que fizeram parte de suas escolhas literárias na juventude. Da literatura africana contemporânea, ela ressalta Alda Espírito Santo (São Tomé e Príncipe), Alda Lara (Angola) e Noémia de Sousa (Moçambique). De outras partes do "meridiano", como explica, apreciava Pearl Buck (Estados Unidos), Anne 
Frank (Alemanha), Catherine Mansfield (Nova Zelândia) e Sophia de Mello Breyner Andresen (Portugal).

Sobre a sua atuação enquanto escritora, de seu processo de escrita, da mulher como centro de suas narrativas e de sua identidade nacional, Orlanda ainda explica no texto do Seminário de Porto Alegre, de 1997, intitulado "O desbravar da escrita":

De mim, Pires Laranjeira ou Ana Maria Martinho, por exemplo, dizem eles que me projetei na minha escrita, eu, desconhecida das lonjuras de Cabo Verde, que me projetei, repito, com resquícios da minha adolescência e infância. Será? Pergunto-me. No desbravar da escrita quase tudo nos surpreende, sem jamais avaliarmos ou adivinharmos se erupções suspeitas no discurso literário ou se do envolvimento da gama de mulheres espreitando e, sorrateiramente, intrometendo-se no espaço ficcional, seriam, na verdade, aqueles seres que queríamos dele fizessem parte. Transbordam no instante em que somos impelidas para a devassa de vidas, de emoções, quando clareiras inesperadas nos surgem sob o nosso olhar. A nós próprias surpreende, ainda, no percurso do deslizar da pena, sem jamais cuidar que, pela calada, confissões insuspeitas espreitarão no comenos de alguma desordenação, chamemo-la assim, indo emaranhar-se no seio das nossas conjecturas. E somos atirados, nós mulheres e homens escritores, para a confissão de sensações e verdades sobrepostas no escorrer de anos, de dias, de estar e conviver. E essas confissões, pensamo-las lisas, despojadas de aberrantes intenções, mas brotadas da necessidade de dizer, de falar com os outros, de revelar, quantas vezes! As nossas perplexidades tidas como verdades (CARVALHAL 1994, p. 139).

Elaine Showater em “The rise of gender" (1989, p. 9) expõe a "afirmação célebre” de Gilbert and Gubar, sobre a pena como metáfora de pênis. No discurso de Amarílis, o comparecimento da pena, estaria ligado à utilização de uma linguagem própria ao discurso masculino? Ao colocar a posição da mulher de "espreitar e sorrateiramente intrometendo-se" no espaço ficcional, revela ainda a necessidade da mulher marcar a sua presença em um universo antes somente legado ao homem?

Amarílis coloca a questão do "deslizar da pena" e da "intromissão da mulher no espaço ficcional", como a experiência da convivência, de estar a (com)viver com a vida dessas mulheres. Nesse aspecto, Benjamin Abdala Junior, aduz a escrita de Orlanda e as marcas femininas em suas narrativas, como uma articulação "ao social e não o contrário, como acontecia com as obras de autoria masculina" o que reforça a capacidade da autora em agravar "uma distonia anterior, que seria de gênero" (2003, p. 299).

A intromissão da mulher no espaço ficcional de Orlanda Amarílis ocorre, portanto, a partir de "confissões insuspeitas" derivadas da "devassa de vidas", que, no contexto cabo- 
verdiano, está fatalmente relacionada ao exílio e à insularidade. Nas próprias palavras da autora "é um mundo feminino, não deliberadamente escolhido. Mulheres saltam para a escrita à revelia" $(1999$, p. 145).

Para Amarilis, narrar Cabo Verde, narrar a diáspora e a insularidade passa, inevitavelmente, pela vida das mulheres dessas ilhas. As que ficam no arquipélago, mães, tias, primas, avós e bisavós coexistem e constroem um espaço feminino de sobrevivência às adversidades do meio, as que partem, certamente carregam a dor de estar longe da "terramãe" e procuram aproximação com seus emigrantes, formando as conhecidas comunidades de cabo-verdianos pelo mundo, nas palavras de Bonnici: “as populações diaspóricas formam comunidades e iniciam os processos de subjetivação através da memória e da identidade" (2009, p. 280). A vivência dessa realidade, para a escritora, "viria a ter eco no que se escreveu" (1997, p. 146).

Sendo ela mesma semelhante a muitas de suas personagens, mulheres de fronteiras, produtos da amalgama de duas culturas, deixa registrada, em seus contos, a força de todas elas, nas palavras de Maria Armandina Maia:

O universo feminino das mulheres que percorrem os vários contos desenvolvem-se a partir da urdidura de percursos femininos diversos, que partilham um traço comum: a extraordinária força de que estão investidas, qualquer que seja a função que lhes é atribuída pela entidade narrativa (MAIA 2007, p. 276).

Orlanda reitera que, como resultado dessa condição de exílio e insularidade, afirma-se a "desilusão, o desencanto e a presença do fantástico", pois esses elementos "fazem parte do nosso imaginário cotidiano" (1997, p. 145). Como conclui Jane Tutikian, o fantástico em Orlanda é “a apreensão mesma da realidade africana, onde é típico que seu aspecto sobrenatural seja tomado por real e natural, numa ligação entre cultura e realidade regidas por qualidades mágicas” (2007, p. 245). Desse modo, o realismo fantástico e as personagens femininas, em suas narrativas, comprovam-se como sendo indissociáveis da cultura caboverdiana.

A língua crioula, por sua vez, também é uma das protagonistas dessas histórias, está presente em quase todas as narrativas de Orlanda. Como resultado providencial da necessidade de se criar uma língua para o comércio e as relações entre escravos e colonos, a língua crioula nasce da articulação do português arcaico com inúmeros dialetos africanos. É a 
convivência entre essa língua mestiça e a língua portuguesa tida como oficial, mas somente falada por um número irrisório da população do arquipélago, que tece o discurso narrativo dos contos de Orlanda.

Assim como a insularidade, a diáspora e a condição da mulher, a língua crioula também se faz presente em toda sua obra. Portanto, o uso do dialeto, a criação de neologismos e o uso do "papiâ"1 em seus contos, expressam a maneira como é composto o texto amariliano, nas palavras de Benjamin Abdala Jr. e Maria Armandina Maia, respectivamente:

Orlanda Amarílis incorpora o "papiâ" cabo-verdiano. As conversas costuram as narrativas (...) A imagem da costura ou tecedura é aqui adequada para explicar o processo de composição de Orlanda Amarílis - uma produção artesanal, restrita aos papeares domésticos. Suas narrativas são sucedâneas, na escrita, dos antigos gritos africanos (ABDAL Jr. 2003, p. 297).

É particularmente intenso o efeito da reprodução de registros de oralidade, "recriados" de contextos e situações que mergulham as suas raízes numa voz profundamente popular, fecunda, um linguajar feito de modos de dizer, provérbios e ladainhas a par do papagueado ou das frases inacabadas, suspensas na ponta da língua e do silêncio, outro grande adjuvante na reconstrução do que designaríamos como uma 'gestualidade verbal' (MAIA 2007, p. 279).

Traçamos acima um panorama dos três elementos essenciais da narrativa de Orlanda Amarílis, todos, como vimos, diretamente relacionados à sua cultura. Como explica Jane Tutikian, podemos entender a cultura em Orlanda como "elemento da afirmação da identidade", de uma identidade "intervalar (...) de quem está na fronteira” (2007, p. 249).

\section{2. "MAIRA DA LUZ" - AS MULHERES-ILHAS DE ORLANDA AMARÍLIS}

fustigada pela escassez de recursos que lhe permitam a sobrevivência, uma inteira população de gente válida, a chamada 'população activa' opta pela partida. Fica um mundo pequeno, reduzido, exíguo, de corpos frágeis que já não encaram a possibilidade de emigrar. São as mulheres, as mães, as crianças que povoam grande parte dos contos (MAIA 2007, p. 271).

O conto "Maira da Luz" discorre sobre a determinação de uma menina em alcançar, por meio dos estudos, a profissão com que sonha: tornar-se médica para, assim, abrir um hospital e uma maternidade na cidade do Mindelo. O conto é antecipado de seu conteúdo por uma epígrafe, que anuncia, mediante o uso dos verbos no subjuntivo e no futuro do presente, a hipótese de uma ação:

1 Derivado do verbo em português "papiar", conversar, falar. 
Se caso perguntassem a Maira da Luz qual a sua premonição quanto ao futuro, ela responderia: ' Vou ser médica. Vou usar uma bata branca como a doutora Maria Francisca. Mandarei construir um hospital novo e uma maternidade [...]' (AMARÍLIS 1989, p. 118).

Maira inicia os estudos no Liceu Central Infante D. Henrique, com aquele mesmo desejo de tornar-se médica. Passa, logo no início das aulas, por um rito de passagem dentro de um colégio dominado por homens. Percebe que se sente bem em companhia masculina e escolhe somente os "melhores-amigos" do sexo oposto:

Aproximou-se e viu-se envolvida pelos colegas, rapazes. Da Praia e, sobretudo, de S. Vicente. Esses eram a maioria. Daí em diante, começou a escolher os melhores amigos, todos do sexo oposto (AMARÍlIS 1989, p. 123).

Apesar de demonstrar inteligência e conseguir sair-se muito bem nas aulas, a situação financeira desfavorável faz com que interrompa os estudos. Vê-se, então, destinada a lecionar em um posto de ensino no Tarrafal (lugar onde se localizavam as prisões e o campo de concentração dos presos políticos das colônias africanas do governo português do Estado Novo), muito longe da cidade do Mindelo/ São Vicente, fervilhante centro intelectual de Cabo Verde, de onde Maira não queria se distanciar.

Victor Barros, em seu livro "Campos de Concentração em Cabo Verde”, 2009, afirma que a instalação da Colônia Penal no Tarrafal, em 1936

representou uma das fortes medidas de endurecimento do regime na produção dos aparelhos repressivos de enquadramento e depuração política e ideológica da sociedade, tendo em conta a perspectiva regeneradora que se pretendia imprimir com a nova ordem de obediência política com vista à criação do homem novo do regime, $(2009$, p. 87).

O conto narra a época mais repressiva do regime em Cabo Verde, pois coloca em cena o momento histórico do fechamento do Liceu Central Infante D. Henrique, ocorrido em 1937 e reaberto em 1975, com o nome de Liceu Gil Eanes. Assim como o fechamento do Liceu, há ainda a denúncia e exílio de professores que criticavam o regime, como o caso do professor de Maira, D. Duarte que, por admirar a educação inglesa, foi "afastado de seus cargos: "afastado do ensino e do hospital onde dava consultas, este aviso servia para todos. Nada de fazer ondas" (AMARÍLIS 1989, p. 123).

O professor Duarte (Abílio Augusto Monteiro Duarte), viveu fora das páginas do conto de Orlanda. Ele foi um dos fundadores do Liceu Gil Eanes, foi ativista e líder político da época da independência. A mudança dos nomes do Liceu, após a denúncia do professor 
Duarte que se apresentava contra o fascismo, no conto, ilustra um momento histórico em Cabo Verde, de luta contra o colonialismo português, no auge de sua repressão. Esses acontecimentos escancaram os desmandos o poder colonial e a política repressiva do Estado Novo português.

A personagem Maira, enquanto mulher e colonizada, não tem chance alguma de vir a tornar-se médica. O desenvolvimento intelectual do colonizado era castrado pelo colonizador, por meio de ações como a extinção dos Liceus, o confinamento de seus intelectuais e a perpetuação da miséria, levando quem desejava mudanças positivas para o arquipélago à imobilização. Tal imobilização aparece, no conto, configurada na metamorfose de Maira em um inseto e o esmagamento desse:

Surpresa maior foi a descoberta de Maira de uns pés enormes quase a pisarem-na e de uma voz a desmoronar-se sobre si, a voz da Cesarina. 'Repare nessa coisa, nesse bicho tão nojento' (...) 'Parece uma carocha, não parece?' (...) 'Parece daquelas carochas mal cheirosas (...) Pois eu a bichos faço assim'. Levantou o pé e esborrachou a nódoa castanha. Um estalido elevou-se no ar (AMARÍLIS 1991, p. 126).

A intertextualidade com a obra "A Metamorfose", de Franz Kafka, 1915, torna-se evidente ao final do conto, quando a personagem transmuta-se em um inseto, que é esmagado por sua rival, Cesarina, "she of the masculine imperial name" (PERES 2002, p. 163). Sobre a metamorfose de Maira, Jane Tutikian retoma o fantástico em Orlanda, explicado em tópico anterior, com relação ao mito:

Da mesma forma, na relação com o mito, Orlanda aporta na relação racional. Há, em seus contos, também possibilidade de revisão da realidade externa pelo fantástico, levando à descoberta de verdades fundamentais através de experiências cotidianas. É o caso de Maira da Luz, de A casa dos mastros, kafkianamente esmagada, feito inseto, pelo meio sócio-histórico. Aí, se corrobora a idéia - ocidental - de que o pensamento mitológico é, por princípio, metafórico, o conteúdo dos mitos não é religioso, apenas se torna (TUTIKIAN 2007, p. 247).

Poderíamos pensar, já que há a presença da metamorfose de Maira em um inseto, assim como a de Gregório, na obra de Kafka, que a transformação parte da opressão. Gregório é constantemente oprimido pelo pai e pelo poder burocrático, que o persegue constantemente. Maira é perseguida por Cesarina, a menina invejosa que consegue um posto de escrevente junto aos negócios de seu tio: "Tio Chico arranjou-me um lugar ao pé dele" (AMARÍLIS 1989: 125). Pode-se concluir que o poder patriarcal protege Cesarina, pois essa se encontra 
"ao pé" do tio, enquanto Maira está desprovida da proteção do pai, do irmão e do tio, tentando vencer por sua própria inteligência e força.

Articulando aspectos próprios de sua cultura, da chamada "identidade de fronteira", característica fundamental de escritores que vivenciam a diáspora, como afirma Bonnici (2009: 278), dentro da chamada literatura pós-colonial, de acordo com Phyllis Peres, as narrativas de Amarílis atuam como "a border writing":

Amarílis narratives problematize the complexities, contradictions and negociations of identity in the lives Cape Verdean woman of different races, religions, cultures and classes.

To understand the works of Orlanda Amarílis, we must first adress the author's national identity and her inscription into a national literature. After all, Amarílis was born in 1924 in colonial Cape Verde at a time Cape Verdians were considered citizens of the Metropolis (...) she writes narratives that are situated in both the archipelago and the European mainland (...) Orlanda Amarílis is unquestioningly called Cape Verdean and/or homogenized into the postcolonial transLusitanian discursive melting pot". Writing on the border signifies a specific position of subjectivity, and, as a Trinh T. Minh-ha reminds us in her work on postcolonial feminism, the recognition of writing as a practice located at the intersection of subject and history. In Amarilis's case, that position straddles borders of nation, race, class, and gender, and her works illustrate the negotiation of identities in the so-called postcolonial world (...) To call Orlanda Amarílis a postcolonial border writer places her in the context of recent critical work on both border and postcolonial writing (PERES 2002, p. 149-150)2.

Como trabalhamos, no tópico anterior, as questões referentes à escrita da cultura, a escrita da identidade cabo-verdiana, que Jane Tutikian, baseada em Homi K. Bhabha (O Local da Cultura, 2007) e Edward Said (Orientalismo, 1990), denominou "terceira margem", uma escrita “intervalar", de quem está na fronteira; acrescentamos a ela, como compreende Phyllis Peres, a escrita pós-colonialista. Dessa forma, Orlanda Amarílis constitui-se como uma "postcolonial border writer".

2 As narrativas de Amarílis problematizam as complexidades, contradições e negociações de identidade nas vidas das mulheres cabo-verdianas de diferentes raças, religiões, culturas e classes. Para entender os escritos de Orlanda Amarílis, nós precisamos, em primeiro lugar, localizar a identidade nacional da autora e a sua inscrição dentro de uma literatura nacional. Afinal, Amarílis nasceu em 1924, no Cabo Verde colonial, em um tempo em que os cabo-verdianos eram considerados cidadãos da Metrópole (...) ela escrevia narrativas que foram situadas em ambos, no Arquipélago e no continente europeu (...) Orlanda Amarílis é, inquestionavelmente, chamada de cabo-verdiana e/ou homogeneizada dentro do caldeirão discursivo translusitano pós-colonial. Escrevendo na fronteira significa uma posição de subjetividade e, como nos lembra Trinh T. Minh-há, em seu trabalho sobre o feminismo pós-colonial, o reconhecimento da escrita como uma prática localizada na intersecção do sujeito e da história. No caso de Amarílis, essa posição ultrapassa fronteiras de nação, raça, classe e gênero, e os seus trabalhos ilustram a negociação de identidade no chamado mundo pós-colonial (...) Chamar Orlanda Amarílis de uma escritora pós-colonial de fronteira enquadra-a no contexto do recente trabalho crítico de ambos escritos: de fronteira e pós-colonial. 
Amarílis e sua "escrita pós-colonial de fronteira" coloca em questão, no conto Maíra da Luz, a realidade da mulher cabo-verdiana da época colonial. A imigração dos homens para Portugal, a fim de realizarem estudos ou trabalharem com o intuito de enviar dinheiro as suas famílias, é retratado no conto de modo a mostrar o não cumprimento desse propósito, ou seja, os homens abandonam a terra natal e seus familiares, passam a viver na Metrópole e muitas vezes constituem novas famílias, como é o caso do irmão e do tio de Maira.

A idade avançada de seu pai (oitenta anos) contrasta com a juventude de sua mãe (quarenta anos), trazendo à tona a viuvez precoce, um aspecto também bastante explorado em seus contos. As mulheres, portanto, nos contos de Orlanda, estão "sós", nas palavras de Maria Aparecida Santilli (1985), ou ainda são "ilhas desafortunadas" como prefere Pires Laranjeira (1989). Ilhas, pois, com relação à diáspora/exílio, estão sempre separadas de seus companheiros, o sexo oposto está sempre ausente, na "terra-longe". Quando permanecem, os poucos homens que ficam ou estão em idade avançada ou cometem algum tipo de violência contra elas. Desafortunadas, pois, como retrata o conto Maira da Luz, muitas vezes a miséria aliada ao poder colonial/patriarcal, faz com que tenham destinos trágicos e seus sonhos pisoteados.

Nesse ponto, podemos localizar a maioria dos escritos de Orlanda na fase da literatura feminina, que Elaine Showater denominará de "feminist". Essa fase da escrita feminina, segundo a autora, está diretamente relacionada aos "protestos contra os valores e padrões vigentes", defendendo "os direitos e valores das minorias" (ZOLIN 2009, p. 330). Ora, no conto, Maira da Luz não alcança o seu sonho, é esmagada como um inseto nojento pela rival, que é favorecida pelo poder patriarcal. Difunde-se, assim, que vencer sozinha, ter liberdade para escolher e desenvolver-se, para a mulher da colônia, era uma utopia.

Apesar de denunciar o abuso contra a mulher, em uma sociedade colonialista/paternalista, Orlanda mescla, pelo menos, duas fases da escrita feminina descritas por Showalter em suas narrativas. A fase feminist está presente maciçamente em seus textos, pois, a todo instante, ela denuncia o esmagador poder paternalista sobre os povos colonizados, especificamente sobre as mulheres, nas quais esses valores ainda não foram superados, e sim, encontram-se no centro das discussões. No entanto, entrevemos uma outra fase, a fase female, quando há a autodescoberta das personagens femininas, na busca de uma identidade própria. 
No conto, podemos ter uma visão conspectiva de uma fase female, quando, por exemplo, as experimentações de Maira deixam revelar parte de sua identidade, de descoberta de si mesma: "descobriu surpreendida: gostava da vida ao ar livre, ao sol, ao calor" (AMARÍLIS 1982, p. 124). Apesar de todas as adversidades que o conto revela sobre a vida de Maira, em um interregno de duas linhas apenas, podemos vislumbrar uma descoberta particular, que diz respeito ao sentir-se no mundo, ao revelar de um gosto próprio, que diz somente respeito a ela, Maira.

Showalter explica que a abordagem cultural da escrita da mulher é a mais completa das teorias desse campo de estudos:

Uma teoria baseada em um modelo da cultura da mulher pode proporcionar, acredito eu, uma maneira de falar sobre a especificidade e a diferença dos escritos femininos mais completa e satisfatória que as teorias baseadas na biologia, na linguística ou na psicanálise. De fato, uma teoria da cultura incorpora ideias a respeito do corpo, da linguagem e da psique da mulher, mas as interpreta em relação aos contextos sociais nos quais elas ocorrem (SHOWALTER 1989, p. 13).

Assim, a obra de Orlanda encontra-se em terrenos cada vez mais fronteiriços: faz parte dos escritores diaspóricos, cuja formação de identidade é complexa. Nas palavras de Bonnici, há uma constante negociação da identidade por sujeitos fragmentados; situa-se dentro da chamada literatura pós-colonial e, ainda, fala da "integração da mulher marginalizada na sociedade" (BONNICI 2009, p. 266-267). Pela identificação desses aspectos, não haveria qualquer outra forma de trabalhar a literatura de Orlanda Amarílis sem ser aquela vincada na abordagem cultural descrita por Showalter.

\section{CONCLUSÃO}

A realidade nos contos de Orlanda Amarílis, como comenta Michel Laban em entrevista à autora, começa a "vacilar". Verificamos esse vacilo ao final do conto "Maira da Luz”. As condições socioeconômicas transformam Maira em um inseto nojento, esmagado pela rival Cesarina: "a insetos nojentos faço assim". O poder paternalista, o modelo da mulher duplamente colonizada está explícito em Maira da Luz, como explica Bonnici: “A mulher é duplamente colonizada pela sociedade e pelo poder colonial” $(2009$, p. 267).

Maira é esmagada por esse sistema, e todos os seus sonhos desaparecem com ela: "Maira da Luz tinha desaparecido sem deixar rastro" (AMARÍLIS 1982, p. 127). Sobrevive a rival, que se protege pelo apadrinhamento, pelo concordar com o poder paternalista: ela é 
indicada por um tio a um cargo "ao pé dele". Concluímos, com a leitura do conto, que a mulher no Cabo Verde colonial, só poderia ocupar cargos semelhantes, aos pés dos homens, jamais se tornariam médicas ou construiriam hospitais e maternidades.

O pensar e o progredir da mulher e da colônia eram inaceitáveis na sociedade colonialista/paternalista do Mindelo colonial. De acordo com o estudo de Phyllis Peres, a transformação de Maira da Luz em um inseto, traça uma intertextualidade com o escritor Franz Kafka e sua obra “A Metamorfose”, 1915. É relida por Orlanda a incapacidade da personagem de Kafka diante do pai, do poder paternalista: Maira é igualmente metamorfoseada em inseto e esmagada por esse poder.

A partir das fases da literatura feminina proposta por Elaine Showalter (1989), o conto de Orlanda, "Maira da Luz", não se enquadra somente nas descrições da chamada fase feminist, pois protesta contra os valores e os padrões vigentes e defende o direito das minorias (denúncia da repressão realizada pelo fascismo português do Estado Novo e da própria sociedade vincada nos padrões paternalistas), mas também demonstra nuances da fase female, pois evidencia, em determinadas passagens, a autodescoberta da personagem Maira (surpreende-se por gostar da vida "ao ar livre, ao sol, ao calor", tem um sonho e procura todos os meios para realizá-lo), ou seja, fora do ambiente doméstico, geralmente legado às mulheres.

No entanto, de acordo com Maria Aparecida Santilli (1985), "a linguagem de Orlanda é ainda a das mulheres contidas, a caminho de libertarem-se do código de manifestações que a sociedade masculina, ao longo dos tempos, lhes impôs”. E ainda completa:

Se desvios de código há, eles dizem muito mais respeito à fala das mulheres em Cabo Verde, em cujas aberturas para o crioulo faz-se um exercício de redação nacional onde a mestiçagem distingue linguisticamente seu texto de qualquer contexto não cabo-verdiano. As mulheres-sós de Orlanda Amarílis, pelo menos nisso, estão 'na sua', caboverdianamente inscritas para sempre na literatura feminina universal (p. 111).

Imobilizada e impossibilitada de realizar seus desejos, Maira representa a mulher da colônia que caminha para a libertação, tanto dos códigos de manifestações que a sociedade masculina lhe impôs, quanto da independência do poder colonial. A aniquilação dos seus sonhos, o seu desaparecimento, e a anulação dela e de sua personalidade ainda dominam a narrativa, mas já é possível perceber, "intrometendo-se" timidamente nesse espaço ficcional, a mulher surpreendida com a sua autodescoberta. 


\section{REFERÊNCIAS:}

ABDALA Jr., Benjamin. Globalização, Cultura e Idealização em Orlanda Amarílis. In: CARVALHAL, Tânia Franco; TUTIKIAN, Jane. Literatura e História: Três vozes de expressão portuguesa - Helder Macedo, José Saramago e Orlanda Amarílis. Porto Alegre: Ed. Universidade UFRGS, 1999.

. Globalização, Cultura e Idealização em Orlanda Amarílis. In: . De vôos e

ilhas - Literatura e Comunitarismos. Cotia: Ateliê Editorial, 2003, p. 287-302.

AMARÍlLIS, Orlanda. A casa dos Mastros - Contos Cabo-verdianos. Prefácio de Pires Laranjeira. Linda-a-Velha: Edições ALAC, 1989.

BARROS, Victor. Campos de Concentração em Cabo Verde - As ilhas como espaço de deportação e de prisão no Estado Novo. Coimbra: Imprensa da Universidade de Coimbra, 2009.

BONNICI, Thomas. Teoria e Crítica Pós-colonialista. In: BONNICI, Thomas, ZOLIN, Lúcia Osana (Org.). Teoria Literária - Abordagens Históricas e Tendências Contemporâneas. $3^{\mathrm{a}}$ Ed. Maringá: UDUEM, 2009, p. 257-285.

CARVALHAL, Tânia Franco, TUTIKIAN, Jane. Literatura e História: Três vozes de expressão portuguesa - Helder Macedo, José Saramago e Orlanda Amarílis. Porto Alegre: Ed. Universidade UFRGS, 1999.

GRECCO, Fabiana M. F. Aventura e Rotina: Gilberto Freyre e a língua portuguesa em Cabo Verde. SIMELP/Évora: 2010, p. 18-34.

KAFKA, Franz. A Metamorfose. Porto Alegre: L\&PMPOCKET, 2001.

LABAN, Michel. Cabo Verde - Encontro com Escritores Vol. I. Porto: Fundação Engenheiro António de Almeida, 1992.

LARANJEIRA, Pires. Ensaios Afro-Literários. $2^{\text {a }}$ Ed. Lisboa: Novo Imbondeiro, 2005.

LOPES, Baltasar. Uma experiência românica nos trópicos. In: FERREIRA, Manuel. Claridade - 50 anos da fundação. Linda-a-Velha, 1986, p. 15-22.

MAIA, Maria Armandina. Orlanda Amarílis - os passos em volta do Ilhéu dos Pássaros. In: MATA, Inocência; PADILHA, Laura C. A Mulher em África - Vozes de uma margem sempre presente. Lisboa: Edições Colobri, 2007, p. 269-281.

PAES, José Paulo. As Dimensões do Fantástico. In: . Gregos \& Baianos. São Paulo: Brasiliense, 1985, p. 184-193. 
PERES, Phyllis. Border Writing, Postcoloniality, and Critical Diference in the works of Orlanda Amarílis. In: QUINLAN, Susan Canty. Lusosex - gender and sexuality in the Portuguese-speaking world. Minnesota: University of Minnesota Press, 2002.

SHOWALTER, Elaine. The Rise of Gender. In: . Speaking of Gender. New York \& London: Routledge, 1989, p. 1-13.

- A crítica feminista no território selvagem. In: BUARQUE DE HOLLANDA, Heloisa (Org.). Tendências e Impasses: o feminino como crítica da cultura. Rio de Janeiro: Rocco, 1994.

TODOROV, Tzvetan. Introdução à Literatura Fantástica. São Paulo: Perspectiva, 1975.

TUTIKIAN, Jane. Por uma Passágada cabo-verdiana. In: MATA, Inocência; PADILHA, Laura C. A Mulher em África - Vozes de uma margem sempre presente. Lisboa: Edições Colobri, 2007, p. 229-251.

ZOLIN, Lúcia Osana. Literatura de Autoria Feminina. In: BONNICI, Thomas; ZOLIN, Lúcia Osana (Org.). Teoria Literária - Abordagens Históricas e Tendências Contemporâneas. $3^{\mathrm{a}}$ Ed. Maringá: UDUEM, 2009, p. 329-336.

Crítica Feminista. In: BONNICI, Thomas; ZOLIN, Lúcia Osana (Org.). Teoria Literária - Abordagens Históricas e Tendências Contemporâneas. $3^{\text {a }}$ Ed. Maringá: UDUEM, 2009, p. 217-242.

RECEBIDO EM: 07 de maio de 2012

APROVADO EM: 14 de junho de 2012 